\title{
LUAS RELUNG DAN KOMPETISI PAKAN KOMUNITAS IKAN DI SITU PANJALU, JAWA BARAT
}

\author{
Astri Suryandari dan Kunto Purnomo \\ Peneliti pada Balai Riset Pemulihan Sumber Daya Ikan, Jatiluhur-Purwakarta \\ Teregistrasi I tanggal: 18 Mei 2009; Diterima setelah perbaikan tanggal: 16 Desember 2009;
}

Disetujui terbit tanggal: 4 Nopember 2010

\begin{abstract}
ABSTRAK
Penelitian ini bertujuan untuk mempelajari luas relung dan kompetisi komunitas ikan di Situ Panjalu. Pengambilan contoh ikan dilakukan pada bulan Mei dan September 2008 dengan menggunakan jaring insang berukuran 2,5; 3,0; dan 3,5 inci. Komunitas ikan di Situ Panjalu terdiri atas ikan nila (Oreochromis niloticus), kongo (Parachromis managuensis), oskar (Amphilophus citrinellus), golsom (Aequidens goldsom), selebra (Amphilopus sp.), dan keril (Aequidens rivulatus). Berdasarkan atas analisis luas relung dan kompetisi pakan, ikan golsom mempunyai potensi untuk berkembang menjadi populasi yang besar di perairan Situ Panjalu dibandingkan jenis ikan lain. Relung pakan yang dapat dioptimalkan adalah fitoplankton sehingga untuk pengkayaan stok dapat dilakukan melalui penebaran ikan herbivora pemakan plankton.
\end{abstract}

KATAKUNCl: $\quad$ luas relung, kompetisi, komunitas ikan,Situ Panjalu

ABSTRACT: $\quad$ Niche breadth and community fish food competition in Situ Panjalu, West Java. By: Astri Suryandari and Kunto Purnomo

The aim of the research was to identified niche breadth and competition among of fishes community in Situ Panjalu. Samples were collected by gill net of 2.5; 3.0; and 3.5 inches mesh size in Mei and September 2008. Fish community in Panjalu consist of tilapia (Oreochromis niloticus), kongo (Parachromis naguensis), midas cichlid (Amphilopus citrinellus), golsom (Aequidens goldsom), selebra (Amphilophus sp.) and keril (Aequidens rivulatus). Based on niche breadth and competition index, goldsom is potentially growth into great population compare to another fishes species in Panjalu. Food niche that could be optimimized was phytoplankton so that stock enhancement could be conducted by stocking the herbivorous fishes feed on phytolankton.

KEYWORDS: $\quad$ niche breadth, competition, fish community, Panjalu Lake

\section{PENDAHULUAN}

Situ Panjalu atau Situ Lengkong terletak di Desa Panjalu, Kabupaten Ciamis, Jawa Barat. Situ yang mempunyai luas 57,95 ha berada pada ketinggian 731 $\mathrm{m}$ di atas permukaan laut. Situ ini memperoleh pasokan air dari mata air dan air hujan. Beberapa fungsi Situ Panjalu antara lain sebagai sumber air irigasi bagi beberapa desa di sekitar perairan, tempat wisata ziarah, dan perikanan (perikanan tangkap dan budi daya sistem keramba).

Jenis-jenis ikan yang terdapat di situ tersebut terdiri atas ikan nila, kongo, oskar, golsom, selebra, dan keril.

Situ Panjalu merupakan situ yang cukup potensial untuk pengembangan usaha perikanan baik perikanan tangkap maupun budi daya. Salah satu upaya pengembangan kegiatan perikanan tangkap adalah melalui pengkayaan stok (stock enhancement). Pengkayaan stok adalah salah satu teknik pengelolaan populasi ikan dengan cara memanipulasi stok yang ada agar populasinya meningkat, misalnya dengan penebaran, penebaran ulang, dan introduksi ikan (Cowx, 1998; Welcomme \& Bartley, 1988 dalam Purnomo, 2000).

Sebelum melakukan penebaran ataupun introduksi ikan pada suatu perairan diperlukan kajiankajian yang mendasar tentang struktur komunitas di perairan tersebut. Selain itu data dan informasi mengenai komposisi atau kebiasaan makan serta bentuk kompetisi yang terjadi antar jenis ikan dalam komunitas merupakan hal yang penting sebagai pertimbangan. Studi kebiasaan makanan dapat memperlihatkan secara mendetil hubungan ekologis di antara organisme (Royce, 1984). Besar dan komposisi dari suplai pakan menentukan komposisi jenis ikan yang ada pada suatu perairan (Nikolsky, 1969).

Populasi ikan yang hidup bersama pada suatu komunitas yang seimbang tergantung pada beberapa faktor, antara lain jumlah macam sumber yang dimanfaatkan oleh setiap kelompok organisme (niche 
breadth), toleransi antar organisme dalam memanfaatkan sumber yang tersedia (niche overlap), dan jumlah total sumber yang dimanfaatkan oleh komunitas ikan tersebut (MacArthur dalam Hespenheide, 1975).

Tujuan penelitian ini adalah untuk mengetahui luas relung dan kompetisi pakan komunitas ikan yang ada di Situ Panjalu.

\section{BAHAN DAN METODE}

Contoh ikan ditangkap pada bulan Mei dan September 2008 di empat stasiun seperti yang disajikan pada Gambar 1 menggunakan alat tangkap jaring insang (gillnet) dengan ukuran mata jaring 2,5; 3 ; dan 3,5 inci.

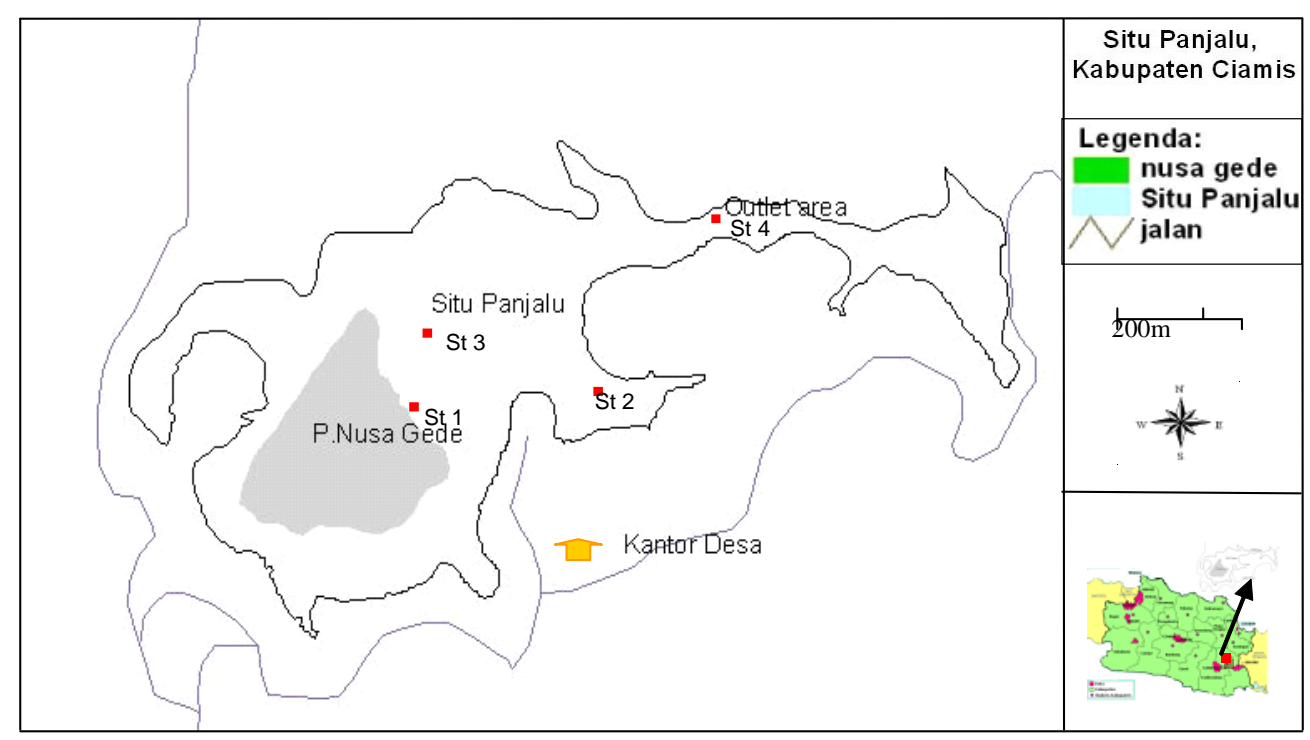

Gambar 1. Lokasi pengambilan contoh di Situ Panjalu, Jawa Barat.

Figure 1. Location of fish sampling in Lake Panjalu, West Java.

Contoh ikan diukur panjang totalnya dengan menggunakan papan ukur serta ditimbang bobotnya dengan menggunakan timbangan dengan ketelitian
$0,1 \mathrm{~g}$. Jumlah total contoh yang diperoleh beserta ukuran dan bobotnya tertera pada Tabel 1 .

Tabel 1. Jenis dan komposisi ikan di Situ Panjalu

Table 1. Fish composition in Lake Panjalu

\begin{tabular}{cllccc}
\hline No. & $\begin{array}{c}\text { Nama lokal/ } \\
\text { Local name }\end{array}$ & $\begin{array}{c}\text { Nama latin/ } \\
\text { Latin name }\end{array}$ & $\begin{array}{c}\text { Jumlah } \\
\text { individu/Number } \\
\text { of individuals }\end{array}$ & $\begin{array}{c}\text { Kisaran panjang } \\
\text { total/The range of } \\
\text { total length (cm) }\end{array}$ & $\begin{array}{c}\text { Kisaran } \\
\text { bobot/The } \\
\text { range of } \\
\text { weight (g) }\end{array}$ \\
\hline 1. & Nila & Oreochromis niloticus & 7 & $10,0-21,0$ & $15,0-198,0$ \\
2. & Kongo & Parachromis managuensis & 7 & $4,8-11,0$ & $3,0-21,0$ \\
3. & Oskar & Amphilophus citrinellus & 7 & $9,0-10,8$ & $13,0-25,0$ \\
4. & Selebra & Amphilopus sp & 9 & $4,5-8,1$ & $3,0-10,0$ \\
5. & Golsom & Aequidens goldsom & 13 & $4,8-7,7$ & $2,0-8,0$ \\
6. & Keril & Aequidens rivulatus & 7 & $5,4-8,2$ & $3,0-12,0$ \\
\hline
\end{tabular}

Contoh ikan dibedah pada bagian perut dan diambil saluran pencernaannya, selanjutnya dimasukan ke dalam plastik dan diberi larutan formalin $4 \%$ sebagai pengawet. Kebiasaan makanan jenis-jenis ikan dianalisis di Laboratorium Biologi Loka Riset Pemacuan Stok Ikan. Organisme makanan yang terdapat dalam lambung diamati dan diidentifikasi di bawah mikroskop binokuler dengan perbesaran 10x20. Pengamatan jenis makanan ikan dilakukan dengan menggunakan metode sapuan dan diidentifikasi mengikuti Bourrelly (1971); Needham \& Needham (1962); Edmonson (1978); Quigley (1977). 
Analisis data untuk mengetahui kebiasan makanan digunakan metode indeks bagian terbesar (indeks of preponderance) yang dirujuk dari Natarajan \& Jhingran (1961) dalam Effendie (1979), yaitu:

$$
\mathrm{Ip}_{\mathrm{i}}=\frac{\mathrm{VixOi}}{\Sigma \mathrm{VixOi}}
$$

di mana:

$\mathrm{Vi}=$ persentase volume makanan ke-i

$\mathrm{O} i=$ persentase frekuensi kejadian makanan ke-i

Ipi $=$ indeks bagian terbesar (indeks of preponderance) makanan ke-i

Luas relung makanan ikan dihitung dengan menggunakan indeks Levin dalam Macpherson (1981) seperti berikut:

$B_{S}=\left[\sum_{i=1}^{S} P_{i j}^{2}\right]^{-1}$

di mana:

$\mathrm{B}_{\mathrm{s}}=$ luas relung spesies $\mathrm{ke}-\mathrm{i}$

$\mathrm{Pij}=$ proporsi jenis makanan ke-i pada makanan spesies ke-j

Analisis kompetisi antar jenis ikan menggunakan Morisita index seperti yang dikatakan oleh Horn (1966) dengan rumus:

$$
\mathrm{Ch}=\frac{2 \sum \text { pij.pik }}{\sum \text { pij }^{2}+{ }^{2} \text { pik }^{2}}
$$

di mana:

$\mathrm{Pij}=$ proporsi jenis makanan ke-i pada spesies ke-j

Pik $=$ proporsi jenis makanan ke-i pada spesies ke-k

\section{HASIL DAN BAHASAN}

Hasil analisis isi perut terhadap enam jenis ikan di Situ Panjalu memperlihatkan bahwa ikan-ikan tersebut memanfaatkan sumber daya makanan alami yang beragam yaitu fitoplankton, tumbuhan, serangga, larva serangga, udang, dan detritus (Gambar 2). Ikan nila cenderung bersifat herbivora dengan pakan utamanya berupa fitoplankton. Ikan kongo, selebra, golsom, dan oscar bersifat omnivora yang memanfaatkan sumber daya pakan beragam mulai dari fitoplankton, tumbuhan air, serangga, sampai udang (Caridina sp.) sedangkan ikan keril cenderung bersifat karnivora dengan makanan berupa serangga, larva serangga, dan ikan.

Hasil analisis terhadap luas relung (niche breadth) dan tumpang tindih relung (niche overlap) tertera pada Tabel 2.

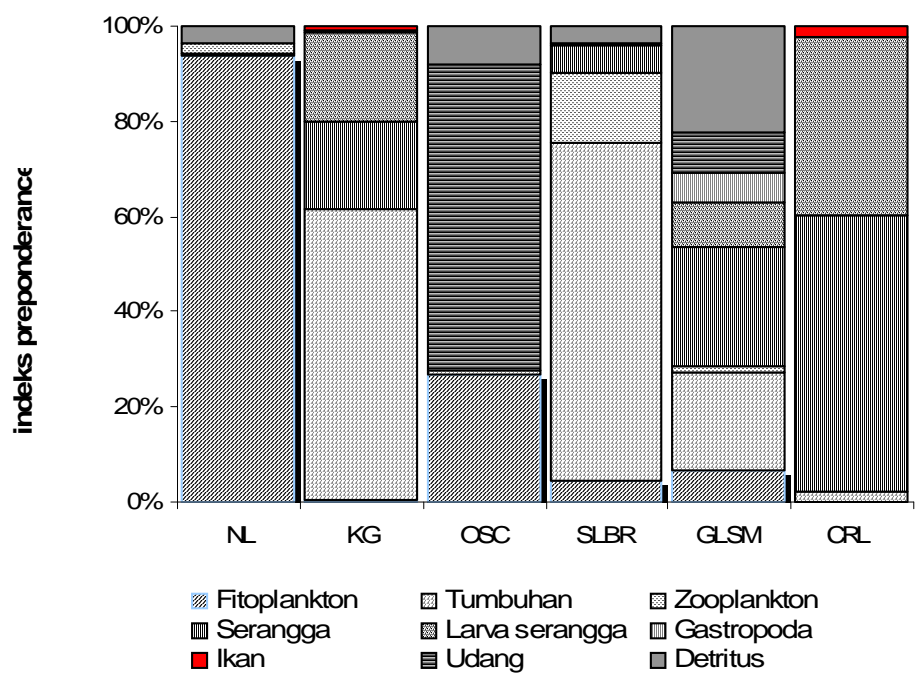

Gambar 2. Komposisi jenis pakan ikan di Situ Panjalu.

Figure 2. Food composition of fishes in Panjalu Lake.

Keterangan $/$ Remarks:NL $=$ Nila, $K G=$ Kongo, OSC $=$ Oscar, SLER $=$ Selebra,

$\mathrm{GLSM}=$ Golsom, $\mathrm{CRL}=$ Keril 
Tabel 2. Luas relung dan tumpang tindih relung pakan ikan-ikan di Situ Panjalu

Table 2. Niche breadth and food niche overlap of fishes in Lake Panjalu

\begin{tabular}{|c|c|c|c|c|c|c|c|}
\hline & \multirow{2}{*}{$\begin{array}{l}\text { Luas relung/ } \\
\text { Niche breadth }\end{array}$} & \multicolumn{6}{|c|}{ Tumpang tindih relung pakan/Food niche overlap } \\
\hline & & NL & KG & OSC & SLBR & GLSM & CRL \\
\hline $\mathrm{NL}$ & 1.130 & & & & & & \\
\hline KG & 2.263 & 0,009 & & & & & \\
\hline OSC & 2.041 & 0,370 & 0,016 & & & & \\
\hline SLBR & 1.886 & 0,070 & 0,914 & 0,044 & & & \\
\hline GLSM & 5.526 & 0,132 & 0,616 & 0,275 & 0,488 & & \\
\hline $\mathrm{CRL}$ & 2.096 & $7 \mathrm{E}-05$ & 0,414 & 0,00046 & 0,100 & 0,568 & \\
\hline
\end{tabular}

Keterangan/Remarks: NL: Nila, KG: Kongo, OSC: Oscar, SLBR: Selebra, GLSM: Golsom, CRL: Keril

Luas relung (niche breadth) dapat menggambarkan pemanfaataan sumber daya pakan suatu organisme luas relung menggambarkan proporsi jumlah jenis sumber daya pakan yang dimanfaatkan oleh suatu jenis ikan (Giller, 1984). Luas relung menunjukan suatu organisme bersifat generalis (relung yang luas) atau spesialis (luas relung sempit) dalam memanfaatkan sumber daya pakan yang tersedia. Organisme dikatakan memiliki relung yang sempit apabila hanya memanfaatkan salah satu sumber daya pakan yang tersedia atau cenderung bersifat spesialis. Hasil analisis menunjukan bahwa luas relung komunitas ikan di Situ Panjalu relatif lebar. Luas relung pakan yang paling luas adalah ikan golsom yaitu 5,526 artinya jenis ikan ini memanfaatkan kelompok makanan dalam jumlah yang banyak dan seimbang. Hal tersebut berarti ikan golsom memiliki kemampuan untuk menyesuaikan terhadap fluktuasi kesediaan pakan dengan baik. Menurut Crowder et al. (1981); Yap (1987) bahwa ikan yang memiliki relung yang luas menunjukan kesuksesan keberadannya di perairan. Ikan golsom di Situ Panjalu memanfaatkan kelompok sumber daya pakan yang beragam secara merata. Ikan tersebut memakan tumbuhan, serangga, larva serangga, detritus, udang, dan moluska. Luasnya relung makanan jenis ikan golsom menunjukan ikan tersebut memiliki peluang untuk menjadi populasi yang besar di perairan Situ Panjalu. Ikan yang memiliki relung yang sempit adalah ikan nila yang hanya mengkonsumsi fitoplankton. Organisme dikatakan memiliki relung yang sempit apabila hanya memanfaatkan salah satu sumber daya makanan yang tersedia atau cenderung bersifat spesialis.

Tumpang-tindih relung (niche overlap) menggambarkan kompetisi antar organisme dalam memanfaatkan sumber daya pakan yang tersedia pada suatu ekosistem. Nilai tumpang-tindih relung mendekati satu menunjukan adanya kesamaan dalam memanfaatkan sumber daya pakan atau peluang kompetisinya tinggi. Nilai tumpang-tindih relung antar jenis ikan di Situ Panjalu berkisar antara 0,000070,914 . Nilai tumpang-tindih relung yang terbesar terjadi pada ikan kongo dengan ikan selebra sedangkan nilai tumpang-tindih yang terkecil terjadi pada ikan nila dengan keril.

Berdasarkan atas nilai luas relung terlihat bahwa ikan kongo, selebra, golsom, keril, dan oskar memiliki relung yang luas $(1,886-5,526)$ sedangkan nilai tumpang-tindih relung yang tinggi (mendekati satu) terjadi antara ikan kongo dengan selebra dan golsom serta antara ikan keril dengan golsom. Dilihat dari dendogram pengelompokan makanan (Gambar 2) terlihat bahwa peluang terjadinya kompetisi antara ikan kongo, selebra, golsom, dan keril tergolong tinggi karena memanfaatkan sumber daya pakan yang sama yaitu tumbuhan dan serangga. Kompetisi antar jenis ikan dilihat dari nilai tumpang-tindih relung pakan, di mana tumpang-tindih relung pakan antara ikan kongo dan selebra $(0,914)$ lebih tinggi dibandingkan antara ikan kongo dan golsom $(0,616)$. Hal ini disebabkan karena selain memanfaatkan tumbuhan dan serangga, ikan golsom juga mengkonsumsi detritus, udang, dan gastropoda yang tidak dikonsumsi oleh ikan kongo dan selebra.

Tumbuhan air menjadi sumber pakan yang dimanfaatkan oleh ikan-ikan di Situ Panjalu seperti ikan kongo, selebra, dan golsom. Apabila pada kondisi di mana sumber pakan berupa tumbuhan tersebut mengalami keterbatasan maka kompetisi yang tinggi akan terjadi pada ikan kongo dan selebra. Untuk ikan golsom yang lebih bersifat generalis akan dapat menyesuaikan diri terhadap perubahan tersebut dengan memanfaatkan sumber daya pakan lain sebagai pakan utama seperti serangga ataupun detritus. Demikian pula sebaliknya apabila terjadi kondisi di mana sumber daya pakan berupa serangga mengalami keterbatasan maka kompetisi terjadi antara ikan keril dengan golsom, namun ikan golsom memiliki peluang untuk menyesuaikan terhadap fluktuasi ketersediaan pakan tersebut dengan memilih sumber pakan lain seperti detritus ataupun tumbuhan. Sementara itu, peluang kompetisi walaupun relatif kecil juga dapat terjadi antara ikan nila dan oskar $(\mathrm{Ch}=0,3)$, yang sama-sama memanfaatkan 
fitoplankton sebagai makanannya. Namun, pada kondisi terjadi gangguan terhadap sumber makanan berupa fitoplankton, ikan oskar memiliki peluang lebih untuk dapat menyesuaikan diri dengan cara memanfaatkan sumber makanan berupa udang. Ikan nila yang memiliki luas relung yang sempit namun kompetisi dengan jenis ikan lain relatif kecil $(0,009)$ juga memiliki peluang untuk menjadi populasi yang besar selama ketersediaan makanan berupa fitoplankton tidak mengalami gangguan.
Berdasarkan atas komposisi pakan, luas relung, dan tumpang-tindih relung tersebut dapat diketahui sumber pakan yang dapat dioptimalkan pemanfaatannya yaitu fitoplankton. Informasi tersebut dapat menjadi salah satu pertimbangan untuk menentukan jenis ikan yang akan dipilih apabila akan melakukan optimalisasi perairan melalui penebaran yaitu jenis ikan yang bersifat planktivor.

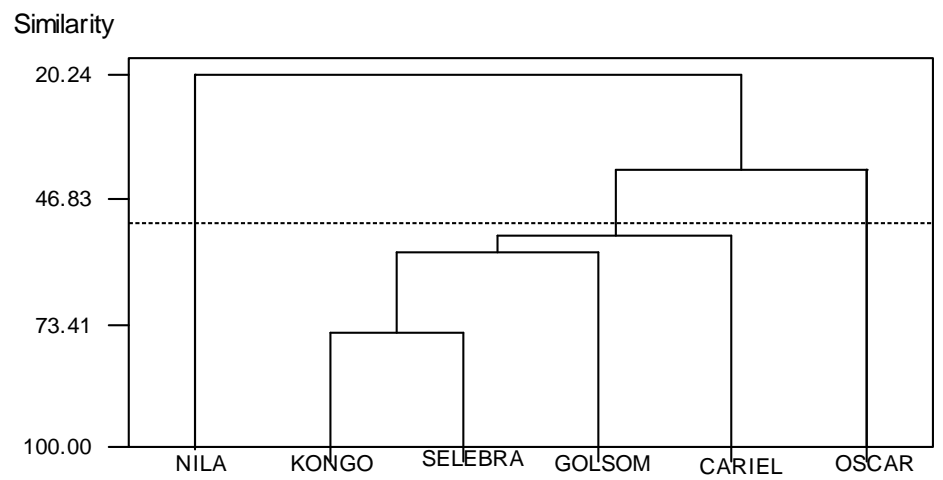

Gambar 2. Analisis pengelompokan pakan komunitas ikan di Situ Panjalu. Figure 2. Cluster analysis of fishes's food in Lake Panjalu.

\section{KESIMPULAN}

1. Komunitas ikan di Situ Panjalu memiliki luas relung yang relatif lebar artinya bahwa komunitas ikan tersebut cenderung bersifat generalis dalam memanfaatkan sumber makanan yang tersedia.

2. Ikan yang memiliki relung terluas adalah ikan golsom sedangkan ikan dengan relung sempit adalah ikan nila. Peluang kompetisi yang tinggi terjadi antara ikan kongo dan selebra.

3. Berdasarkan atas analisis luas relung dan kompetisi pakan, ikan golsom mempunyai potensi untuk berkembang menjadi populasi yang besar di perairan Situ Panjalu dibandingkan jenis ikan lain.

4. Peluang untuk pengembangan ikan planktivora (pemakan plankton) di Situ Panjalu besar mengingat relung pakan tersebut hanya ditempati oleh ikan nila.

\section{PERSANTUNAN}

Tulisan ini merupakan kontribusi dari kegiatan riset pengembangan culture based fisheries di perairan Waduk/Danau/Situ di Provinsi Jawa Barat dan Jawa Tengah, T. A. 2008, di Loka Riset Pemacuan Stok Ikan-Jatiluhur, Purwakarta.

\section{DAFTAR PUSTAKA}

Bourrelly, P. 1971. Les algues D'eau douce Initiation à la Systematique. Edition IV. Boubée \& Cie. 3. Place Saint Andre-des-Arts. Paris.

Cowx, I. G. 1998. Stocking and Introduction of Fish. Fishing News Books a Division of Blackwell Science Ltd. Australia.

Crowder, L. B., J. J. Magnuson, \& S. B. Brandt. 1981. Complemetarity in the use of food and thermal habitat by Lake Michigan Fishes. Can. J. Fish. Aquat. Sci. 38: 662-668.

Edmonson, W. T. 1978. Freshwater Biology. Second Edition. University of Washington. Seattle.

Effendie, M. I. 1979. Metoda Biologi Perikanan. Cetakan Pertama. Yayasan Dewi Sri. Bogor.

Giller, P. S.1984. Community Structure and the Niche. Chapman and Hall. New York. 153 pp.

Hespenheide, H. A. 1975. Prey caracteristics and predator niche width. Ecology and evolution of communities. Martmel and Diamond (Editor). The Belknap Press of Harvard Univ. Press Cambrige. Massachusetts and London. England. 158-179. 
Horn, H. S. 1966. Measurement of overlap in comparative ecological studies. Am. Nat. 100 (914): 419-423.

Macpherson, E. 1981. Resource partitioning in Mediterranean Demersal Fish Community. Marine Ecology-Preogress Series. (4): 183-193.

Needham, J. G. \& P. R. Needham. 1962. A Guide to the Study of Freshwater Biology. Constable \& Co. Ltd. London.

Nikolsky, G. V. 1969. The Ecology of Fishes. Academic Press. London.
Purnomo, K. 2000. Kompetisi dan pembagian sumber daya pakan komunitas ikan di Waduk Wonogiri. Jurnal Penelitian Perikanan Indonesia. (6): 3-4.

Quigley, M. 1977. Invertebrates of Stream and Rivers, a Key to Identification. Edward Arnold Ltd. 25 Hill Street. London.

Royce, W. 1984. Introduction to the Practice of Fishery Science. Academic Press Inc. New York. 428. 